\title{
Dissociation in control of physiological and behavioral responses to emotional stress by cholinergic neurotransmission in the bed nucleus of the stria terminalis in rats
}

\author{
Marianna K. Gouveia ${ }^{a}$, Tarciso T. Miguel ${ }^{b}$, Cristiane Busnardo ${ }^{c}$, América A. Scopinho ${ }^{c}$,

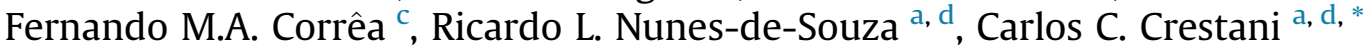 \\ ${ }^{a}$ Laboratory of Pharmacology, School of Pharmaceutical Sciences, Univ. Estadual Paulista-UNESP, Araraquara, SP, Brazil \\ ${ }^{\mathrm{b}}$ Institute of Biomedical Sciences, Federal University of Uberlândia (UFU), Uberlândia, MG, Brazil \\ c Department of Pharmacology, School of Medicine of Ribeirão Preto, University of São Paulo, Ribeirão Preto, SP, Brazil \\ d Joint UFSCar-UNESP Graduate Program in Physiological Sciences, São Carlos, SP, Brazil
}

\section{A R T I C L E I N F O}

\section{Article history:}

Received 25 June 2015

Received in revised form

3 October 2015

Accepted 10 October 2015

Available online 23 October 2015

\section{Keywords:}

Anxiety

BNST

Cardiovascular

Corticosterone

Elevated plus maze

Extended amygdala

Muscarinic receptors

\begin{abstract}
A B S T R A C T
The bed nucleus of the stria terminalis (BNST) is a forebrain structure implicated in physiological and behavioral responses to emotional stress. However, the local neurochemical mechanisms mediating the BNST control of stress responses are not fully known. Here, we investigated the involvement of BNST cholinergic neurotransmission, acting via muscarinic receptors, in cardiovascular (increase in blood pressure and heart rate and fall in tail skin temperature) and neuroendocrine (increase in plasma corticosterone) responses and behavioral consequences (anxiogenic-like effect in the elevated plusmaze) evoked by acute restraint stress in rats. Bilateral microinjection into the BNST of either the choline uptake inhibitor hemicholinium-3 (3 nmol/100 nl) or the muscarinic receptor antagonist methylatropine $(3 \mathrm{nmol} / 100 \mathrm{nl}$ ) enhanced the heart rate increase and inhibited the anxiogenic-like effect observed in the elevated plus-maze evoked by restraint. However, neither hemicholinium-3 nor methylatropine affected the increase in blood pressure and plasma corticosterone levels and the fall in tail skin temperature. Facilitation of local cholinergic signaling by microinjection of the acetylcholinesterase inhibitor neostigmine $(0.1 \mathrm{nmol} / 100 \mathrm{nl})$ into the BNST reduced restraint-evoked pressor and tachycardiac responses and the fall in tail cutaneous temperature, without affecting the increase in plasma corticosterone. All effects of neostigmine were completely abolished by local BNST pretreatment with methylatropine. These findings indicate an opposite role of BNST cholinergic neurotransmission, acting via local muscarinic receptor, in control of cardiovascular responses (inhibitory influence) and emotional consequences (facilitatory influence) evoked by restraint stress. Furthermore, present findings provide evidence that BNST control of neuroendocrine responses to stress is mediated by mechanisms others than local cholinergic signaling.
\end{abstract}

(c) 2015 Elsevier Ltd. All rights reserved.

\section{Introduction}

A coordinated and complex set of physiological changes is generated during aversive threats, which constitute important adaptive responses maintaining the homeostasis (Dampney et al., 2008; Danese and McEwen, 2012; Sterling, 2012; Ulrich-Lai and Herman, 2009). Cardiovascular changes include blood pressure and

\footnotetext{
* Corresponding author. Laboratory of Pharmacology, Department of Natural Active Principles and Toxicology, School of Pharmaceutical Sciences, São Paulo State University - UNESP, Rodovia Araraquara-Jau Km 01 (Campus Universitário), 14801 902, Caixa Postal 502, Araraquara, SP, Brazil.

E-mail address: cccrestani@yahoo.com.br (C.C. Crestani).
}

heart rate (HR) increases; hemodynamics alterations characterized by vasodilatation in skeletal muscle and vasoconstriction in splanchnic, renal and cutaneous beds; and modulation of baroreflex activity (Blessing, 2003; Crestani et al., 2010; Dos Reis et al., 2014; Schadt and Hasser, 1998). The vasoconstriction in skin territory leads to a drop in the cutaneous temperature (Oliveira et al., 2015; Vianna and Carrive, 2005). Activation of the hypothalamic-pituitary-adrenocortical (HPA) axis is a characteristic neuroendocrine response to stress (Dickerson and Kemeny, 2004; Ulrich-Lai and Herman, 2009). In addition to physiological responses, stressful events also evoke emotional changes that can be identified in rodents through analysis of anxiety- and depressionlike behaviors (Busnardo et al., 2013; Padovan and Guimaraes, 
2000; Sevgi et al., 2006). Although importance of stress responses, the neurobiological mechanisms involved in physiological and behavioral changes to aversive threats is poorly understood.

The brain triggers the responses during emotional stress through action of several neurochemical mechanisms (Joels and Baram, 2009; Ulrich-Lai and Herman, 2009). The bed nucleus of the stria terminalis (BNST) is a limbic forebrain structure implicated in control of cardiovascular and neuroendocrine functions and behavioral responses (Crestani et al., 2013; Davis et al., 2010). Both an inhibitory and facilitatory role of the BNST in cardiovascular and neuroendocrine responses to stress has been reported, depending on the type of aversive stimulus and the BNST region investigated (for review, see Crestani et al. (2013)). Regarding the behavioral reactivity to stress, it was demonstrated an involvement of the BNST in reduction of food intake (Ohata and Shibasaki, 2011) and anxiogenic effect evoked by aversive threats (Cecchi et al., 2002; Khoshbouei et al., 2002). Although these results indicate a role of the BNST in physiological and behavioral responses to stress, the local neurochemical mechanisms involved in this control was not fully elucidated.

Acetylcholine is released in several limbic structures during aversive stimuli (Mark et al., 1996; Nail-Boucherie et al., 2000). Indeed, convergent evidence has indicated a role of this signaling mechanism in controlling stress responses in several limbic structures (Bhatnagar et al., 1997; Fortaleza et al., 2009; Helm et al., 2004; Kubo et al., 2003). Cholinergic terminals as well as muscarinic and nicotinic cholinergic receptors were detected within the BNST (Clarke et al., 1985; Guo et al., 2012; Ruggiero et al., 1990; Spencer et al., 1986; Wamsley et al., 1984). Activation of muscarinic receptors seems to be the primary mechanism mediating acetylcholine actions in the BNST. For instance, modulation of firing activity of BNST neurons by acetylcholine is inhibited by muscarinic receptor antagonists, without being affected by nicotinic receptor blockers (Casada and Dafny, 1993; Guo et al., 2012). Moreover, microinjection of cholinergic agonists into the BNST evokes blood pressure increase and reduces baroreflex activity via muscarinic receptors (Alves et al., 2007; Nasimi and Hatam, 2011). A role of BNST cholinergic neurotransmission in control of neuroendocrine functions through local muscarinic receptors has also been described (Alves et al., 2011; Crestani et al., 2013).

Activation of muscarinic cholinergic receptors within the BNST evokes physiological responses similar to those observed during stress (Alves et al., 2007; Nasimi and Hatam, 2011). However, a possible involvement of BNST cholinergic neurotransmission in stress responses has never been evaluated. Therefore, in the present study we evaluated the involvement of cholinergic signaling within the BNST, acting via local muscarinic receptors, in cardiovascular and neuroendocrine responses and anxiogenic-like effects evoked by acute restraint stress. Restraint stress is a widely utilized experimental model to study the emotional and behavioral responses to stress. It is an unavoidable and unconditioned aversive situation that leads to HPA axis activation; cardiovascular responses; and behavioral changes, such as reduced exploration of open arms of the elevated plus-maze (EPM) (Busnardo et al., 2013; Choi et al., 2007; Dos Reis et al., 2014; Padovan and Guimaraes, 2000).

\section{Material and methods}

\subsection{Animals}

Ninety-five male Wistar rats weighting 240-260 g (60-daysold) were used in the present study. Animals were obtained from the animal breeding facility of the Univ. Estadual Paulista-UNESP (Botucatu, SP, Brazil) and were housed in plastic cages in a temperature-controlled room $\left(24^{\circ} \mathrm{C}\right)$ in the Animal Facility of the Laboratory of Pharmacology/School of Pharmaceutical Sciences/ UNESP. They were kept under a 12:12 h light-dark cycle (lights on between 7:00 $\mathrm{h}$ and 19:00 $\mathrm{h}$ ) and had free access to water and standard laboratory food. Housing conditions and experimental procedures were approved by the Ethical Committee for Use of Animals of the School of Pharmaceutical Science/UNESP, which complies with Brazilian and international guidelines for animal use and welfare.

\subsection{Surgical procedures}

Five days before the trial, rats were anesthetized with tribromoethanol (250 mg/kg, i.p.) and their heads fixed to a stereotaxic apparatus (Stoelting, Wood Dale, Illinois, USA). After scalp anesthesia with $2 \%$ lidocaine the skull was exposed and stainlesssteel guide cannulas (26G, $12 \mathrm{~mm}$-long) were bilaterally implanted into the BNST at a position $1 \mathrm{~mm}$ above the site of injection. Stereotaxic coordinates for cannula implantation into the BNST were: antero-posterior $=+8.6 \mathrm{~mm}$ from interaural; lateral $=4.0 \mathrm{~mm}$ from the medial suture, ventral $=-5.8 \mathrm{~mm}$ from the skull with a lateral inclination of $23^{\circ}$ (Paxinos and Watson, 1997). Cannulas were fixed to the skull with dental cement and one metal screw. Immediately after end of the surgery procedures, the animals received a streptomycin and penicillin polyantibiotic formulation to prevent infection ( $560 \mathrm{mg} / \mathrm{ml} / \mathrm{kg}$, i.m.) and the nonsteroidal anti-inflammatory flunixine meglumine for postoperation analgesia $(0.5 \mathrm{mg} / \mathrm{ml} / \mathrm{kg}$, s.c.).

One day before the experiment, rats were anesthetized with tribromoethanol $(250 \mathrm{mg} / \mathrm{kg}$, i.p.) and a catheter (Clay Adams, Parsippany, NJ, USA) filled with a solution of heparin $(50 \mathrm{UI} / \mathrm{ml}$, Hepamax-S ${ }^{\circledR}$, Blausiegel, Cotia, SP, Brazil) diluted in saline $(0.9 \%$ $\mathrm{NaCl}$ ) was inserted into the abdominal aorta through the femoral artery for cardiovascular recording and blood samples collection. The catheter was tunneled under the skin and exteriorized on the animal's dorsum. Immediately after end of the surgery procedures, the non-steroidal anti-inflammatory flunixine meglumine was administered for post-operation analgesia $(0.5 \mathrm{mg} / \mathrm{ml} / \mathrm{kg}$, s.c.). The animals were kept in individual cages during the postoperative period and experimental procedures and did not show signs of pain or discomfort on the trial day, thus indicating a proper recovery from surgeries.

\subsection{Blood pressure and heart rate recording}

The cannula implanted into the femoral artery was connected to a pressure transducer (DPT100, Utah Medical Products Inc., Midvale, UT, USA). The pulsatile blood pressure was recorded using an amplifier (Bridge Amp, ML224, ADInstruments, Australia) and an acquisition board (PowerLab 4/30, ML866/P, ADInstruments, NSW, Australia). Mean arterial pressure (MAP) and heart rate (HR) values were derived from the pulsatile arterial pressure.

\subsection{Cutaneous temperature measurement}

The tail skin temperature was recorded using a thermal camera (IRI4010, Infra Red Integrated Systems Ltd., Northampton, UK). The temperature was measured on five points of the animal's tail and the mean value was calculated for each recording (Busnardo et al., 2013; Oliveira et al., 2015).

\subsection{Plasma corticosterone measurement}

Plasma corticosterone concentration was measured by radioimmunoassay. The method was adapted from that described 
previously (Sarnyai et al., 1992). Briefly, $20 \mu$ l of plasma was diluted 50 times with $0.01 \mathrm{M} \mathrm{PBS}$ and placed in a water bath at $75^{\circ} \mathrm{C}$ for $1 \mathrm{~h}$ for heat inactivation of corticosteroid binding globulin. One hundred microliters of a solution of antibody (Sigma-Aldrich, USA) and $(3 \mathrm{H})$-corticosterone $(10,000-20,000 \mathrm{cpm} / \mathrm{ml})$ (New England Nuclear, Boston, MA, USA) was added to each sample, mixed and incubated overnight at $4{ }^{\circ} \mathrm{C}$. Dextran-coated charcoal was used to adsorb free steroid after incubation. Tubes were centrifuged at $2000 \times \mathrm{g}$ for $15 \mathrm{~min}$ at $4{ }^{\circ} \mathrm{C}$, the supernatant from each tube was transferred to scintillation vials and the radioactivity was quantified by liquid scintillation spectrometry. Standard curves were constructed using 25, 50,100, 250, 500, 750, 1000 and $2000 \mathrm{pg} /$ $100 \mu \mathrm{l}$ of corticosterone (Sigma-Aldrich, USA). After dilution, all concentrations of corticosterone samples were within the linear range of the standard curve.

\subsection{Restraint stress}

Animals were subjected to restraint by placing each rat in a plastic cylindrical restraint tube (diameter $6.5 \mathrm{~cm}$, length $15 \mathrm{~cm}$ ) ventilated by holes ( $1 \mathrm{~cm}$ diameter) that comprised approximately $20 \%$ of the tube surface. Immediately after the end of the stress exposure rats were returned to their home cages. Each rat was submitted only to one session of restraint in order to avoid habituation.

\subsection{Elevated plus maze}

The EPM test was conducted as described before (Busnardo et al., 2013; Padovan and Guimaraes, 2000). Briefly, the apparatus consisted of two opposite open arms $(50 \times 10 \mathrm{~cm})$ crossed at a right angle by two arms of the same dimensions enclosed by $40 \mathrm{~cm}$ high walls with no roof. The maze was located $50 \mathrm{~cm}$ above the floor. Rodents naturally avoid the open arms of the EPM and anxiolytic compounds typically increase the exploration of these arms without changing the number of enclosed-arm entries (Pellow and File, 1986). Therefore, behavioral measures were the frequency of closed-arm entries (CE) and the percentage of open-arm entries (\% $\mathrm{OE}$ ) and percentage of open-arm time (\%OT). All sessions were videotaped and analysis was realized in a blinded manner using the software Any-maze ${ }^{\circledR}$ (Stoelting, Wood Dale, Illinois, USA).

\subsection{Microinjection into the BNST}

The needles (33G, Small Parts, Miami Lakes, FL, USA) used for microinjection were $1 \mathrm{~mm}$ longer than the guide cannulas implanted into the BNST and were connected to a $2 \mu \mathrm{L}$ syringe (7002-KH, Hamilton Co., Reno, NV, USA) through a piece of PE-10 polyethylene tubing (Clay Adams, Parsippany, NJ, USA). Needles were carefully inserted into the guide cannulas without restraining the animals, and drugs were injected in a final volume of $100 \mathrm{~nL}$ (Crestani et al., 2009; Oliveira et al., 2015).

\subsection{Drugs and solutions}

Hemicholinium-3 (choline uptake inhibitor) (Sigma-Aldrich, St. Louis, Missouri, USA), methylatropine bromide (muscarinic cholinergic receptor antagonist) (Sigma-Aldrich), neostigmine bromide (acetylcholinesterase inhibitor) (Sigma-Aldrich), tribromoethanol (Sigma-Aldrich), and urethane (Sigma-Aldrich) were dissolved in saline ( $\mathrm{NaCl} 0.9 \%)$. Flunexine meglumine (Banamine $^{\circledR}$, Schering Plough, Cotia, SP) and the poly-antibiotic preparation with streptomycins and penicillins (Pentabiotico ${ }^{\circledR}$, Fort Dodge, Campinas, SP, Brazil) were used as provided.

\subsection{Experimental procedures}

Animals were brought to the experimental room in their own cages. Animals were allowed at least $60 \mathrm{~min}$ to adapt to the experimental room conditions, such as sound and illumination, before starting the experiments. The experimental room was temperature controlled $\left(24^{\circ} \mathrm{C}\right)$ and acoustically isolated from the other rooms.

\subsubsection{Effect of bilateral microinjection into the BNST of} hemicholinium-3 or methylatropine in cardiovascular and neuroendocrine responses to acute restraint stress

This protocol aimed to investigate whether BNST cholinergic neurotransmission, acting via muscarinic receptors, modulates cardiovascular and neuroendocrine responses evoked by acute restraint stress. For this, independent groups of animals received bilateral microinjection into the BNST of the choline uptake inhibitor hemicholinium-3 (3 nmol/100 nl), the muscarinic cholinergic receptor antagonist methylatropine (3 nmol/100 $\mathrm{nl}$ ), or vehicle (saline, $100 \mathrm{nl}$ ). Ten minutes later, the animals were subjected to a 30 min session of restraint. The treatment protocol (timing and doses) was based in previous studies from our group (Alves et al., 2007; Fernandes et al., 2005; Fortaleza et al., 2009). The duration of stress session was based in previous studies that reported a role of the BNST in controlling cardiovascular and HPA axis responses to restraint (Choi et al., 2007; Oliveira et al., 2015; Radley et al., 2009).

Cardiovascular recordings began at least $30 \mathrm{~min}$ before the onset of the restraint and were performed throughout the period of exposure to the restraint stress. The tail skin temperature was measured 10, 5 and 0 min before the restraint for baseline values, and at every 5 min during restraint. Blood samples $(\sim 200 \mu \mathrm{l})$ for the determination of plasma corticosterone concentration were collected from the femoral artery catheter immediately before (basal level) and 15 and 30 min after onset of the restraint.

\subsubsection{Effect of unilateral microinjection into the BNST of methylatropine and/or neostigmine in cardiovascular and neuroendocrine responses to acute restraint stress}

In order to confirm a role of BNST cholinergic neurotransmission in physiological responses to restraint stress, we investigated the effects of facilitation of cholinergic signaling within the BNST in restraint-evoked cardiovascular and neuroendocrine responses. We also evaluated whether these effects were mediated by activation of local muscarinic receptors. For this, independent groups of animals received unilateral microinjection into the BNST of methylatropine ( $3 \mathrm{nmol} / 100 \mathrm{nl}$ ) or vehicle (saline, $100 \mathrm{nl}$ ) followed, 5 min later, by unilateral injection of the acetylcholinesterase inhibitor neostigmine $(0.1 \mathrm{nmol} / 100 \mathrm{nl}$ ) or vehicle (saline, $100 \mathrm{nl}$ ). Five minutes after BNST pharmacological treatment, the animals underwent a $30 \mathrm{~min}$ session of restraint stress. Cardiovascular recording, cutaneous temperature measurement, and blood sampling were realized as described above. The treatment protocol (timing and doses) was based in previous studies from our group (Alves et al., 2007; Fernandes et al., 2005; Fortaleza et al., 2009).

2.10.3. Effect of bilateral microinjection of hemicholinium-3 or methylatropine into the BNST on behavioral responses to acute restraint stress

This protocol aimed to investigate an involvement of BNST cholinergic neurotransmission, acting through muscarinic receptors, in anxiogenic-like effects induced by restraint stress. For this purpose, animals were divided into four experimental groups: (1) naïve group, which was not subjected to restraint stress and not subjected to any pharmacological treatment; (2) vehicle group 

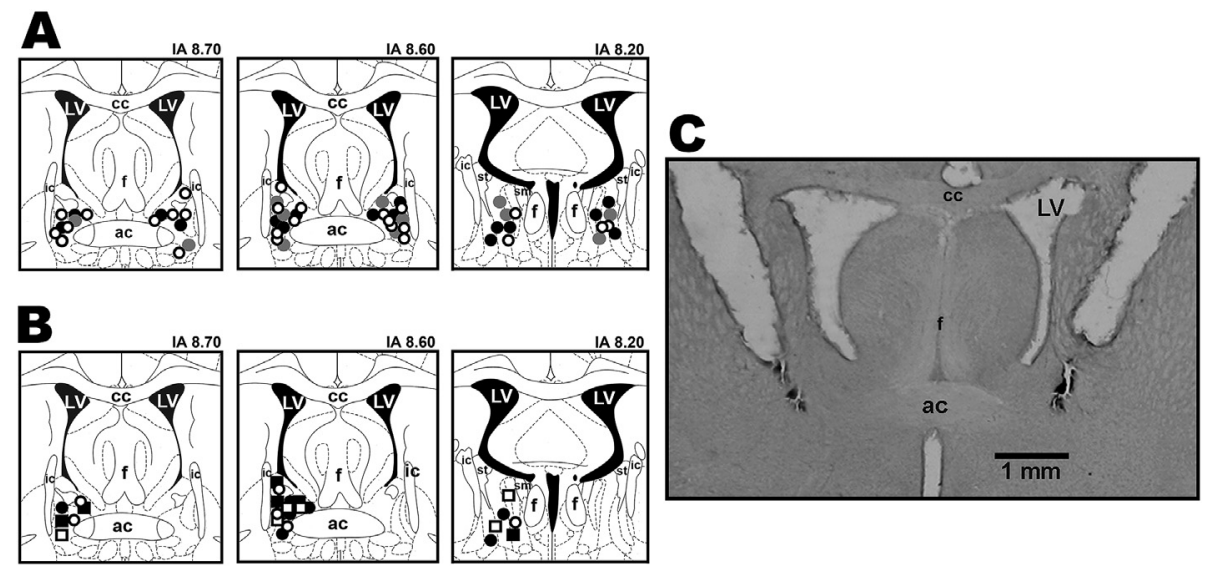

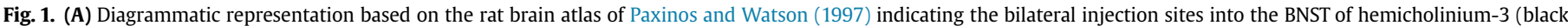

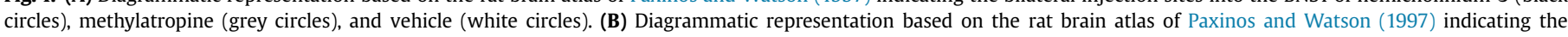

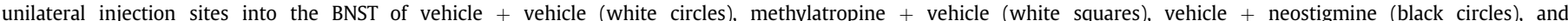

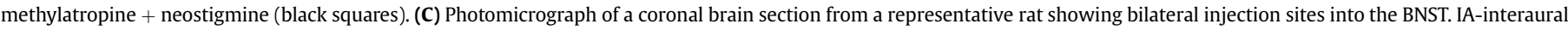
coordinate; ac-anterior commissure; cc-corpus callosum; f-fornix; ic-internal capsule; LV- lateral ventricle; sm-stria medullaris, st-stria terminalis.

$(100 \mathrm{nl})$, which saline was bilaterally microinjected into the BNST before exposure to restraint; (3) hemicholinium-3 group, which the choline uptake inhibitor hemicholinium-3 (3 nmol/100 nl) was bilaterally microinjected into the BNST before the restraint session; and (4) methylatropine group, which the muscarinic cholinergic receptor antagonist methylatropine $(3 \mathrm{nmol} / 100 \mathrm{~nL}$ ) was bilaterally microinjected into the BNST before restraint.

As previously described (Busnardo et al., 2013; Padovan and Guimaraes, 2000), experiments were realized in two days. In the first day, animals underwent a 60 min session of restraint stress 10 min after BNST pharmacological treatment. Twenty-four hours after the end of restraint session, all rats were tested in the EPM. Animals in naïve group were left undisturbed in the first day, but were tested in the EPM in the second day.

\subsection{Histological determination of the microinjection sites}

At the end of experiments, animals were anesthetized with urethane $(1.25 \mathrm{~g} / \mathrm{kg}$, i.p.) and $100 \mathrm{~nL}$ of $1 \%$ Evan's blue dye was injected into the BNST as a marker of the injection site. Brains were removed and post-fixed in $10 \%$ formalin for at least $48 \mathrm{~h}$ at $4{ }^{\circ} \mathrm{C}$. Then, serial $40 \mu \mathrm{m}$-thick sections of the BNST region were cut with a cryostat (CM1900, Leica, Wetzlar, Germany). The actual placement of the microinjection needles was determined according to the rat brain atlas of Paxinos and Watson (1997) by analyzing the serial sections under a light microscopy.

\subsection{Data analysis}

Data were expressed as the means \pm SEM. The basal values of MAP, HR, tail skin temperature and plasma corticosterone concentration were compared using Student's t-test or one-way ANOVA. The time-course of change in plasma corticosterone concentration and cardiovascular parameters were analyzed using repeated measures ANOVA with treatment as between factor and time as within factor. A post hoc t-test with a Bonferroni correction was used for identification of differences between the groups. The behavioral measures in the EPM were analyzed using one-way ANOVA followed by Bonferroni's post hoc test. Results of statistical tests with $\mathrm{P}<0.05$ were considered significant.

\section{Results}

A diagrammatic representation showing bilateral sites of microinjection into the BNST of all animals used in the present study and a photomicrograph of a coronal brain section depicting bilateral microinjection sites in the BNST of one representative animal is presented in Fig. 1.

\subsection{Effect of bilateral microinjection into the BNST of hemicholinium-3 or methylatropine in cardiovascular and neuroendocrine responses to acute restraint stress}

\subsubsection{Hemicholinium-3}

Bilateral microinjection of the choline uptake inhibitor hemicholinium-3 (3 nmol/100 $\mathrm{nl})$ into the BNST did not alter baseline values of either MAP, HR, tail skin temperature, or plasma corticosterone (Table 1). Restraint increased the MAP $\left(\mathrm{F}_{(16,221)}=32.99, \mathrm{P}<0.0001\right), \mathrm{HR}\left(\mathrm{F}_{(16,221)}=45.45, \mathrm{P}<0.0001\right)$, and plasma corticosterone $\left(\mathrm{F}_{(2,39)}=32.94, \mathrm{P}<0.0001\right)$; and decreased the tail cutaneous temperature $\left(\mathrm{F}_{(8,117)}=18.61, \mathrm{P}<0.0001\right)$ (Fig. 2$)$. BNST treatment with hemicholinium-3 enhanced the restraint-

Table 1

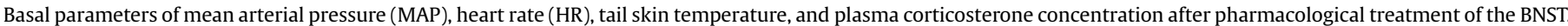

\begin{tabular}{|c|c|c|c|c|c|}
\hline Group & $\mathrm{n}$ & $\begin{array}{l}\text { MAP } \\
(\mathrm{mmHg})\end{array}$ & $\begin{array}{l}\mathrm{HR} \\
(\mathrm{bpm})\end{array}$ & $\begin{array}{l}\text { Tail skin temperature } \\
\left({ }^{\circ} \mathrm{C}\right)\end{array}$ & $\begin{array}{l}\text { Plasma corticosterone } \\
(\mu \mathrm{g} / \mathrm{dl})\end{array}$ \\
\hline Vehicle & 7 & $102 \pm 1$ & $350 \pm 5$ & $29.0 \pm 0.5$ & $16 \pm 4$ \\
\hline Hemicholinium-3 & 8 & $101 \pm 2$ & $358 \pm 3$ & $28.3 \pm 0.7$ & $18 \pm 7$ \\
\hline Vehicle & 6 & $103 \pm 2$ & $353 \pm 5$ & $28.3 \pm 0.3$ & $17 \pm 2$ \\
\hline Methylatropine & 6 & $100 \pm 2$ & $362 \pm 8$ & $28.9 \pm 0.8$ & $20 \pm 2$ \\
\hline Vehicle + Vehicle & 6 & $99 \pm 3$ & $354 \pm 6$ & $28.5 \pm 0.5$ & $22 \pm 3$ \\
\hline Methylatropine + Vehicle & 6 & $101 \pm 3$ & $366 \pm 8$ & $29.0 \pm 0.4$ & $21 \pm 2$ \\
\hline Vehicle + Neostigmine & 8 & $100 \pm 1$ & $353 \pm 4$ & $28.2 \pm 0.6$ & $18 \pm 2$ \\
\hline Methylatropine + Neostigmine & 6 & $99 \pm 2$ & $363 \pm 6$ & $28.2 \pm 0.5$ & $20 \pm 5$ \\
\hline
\end{tabular}

No significant difference in all comparisons was observed. 

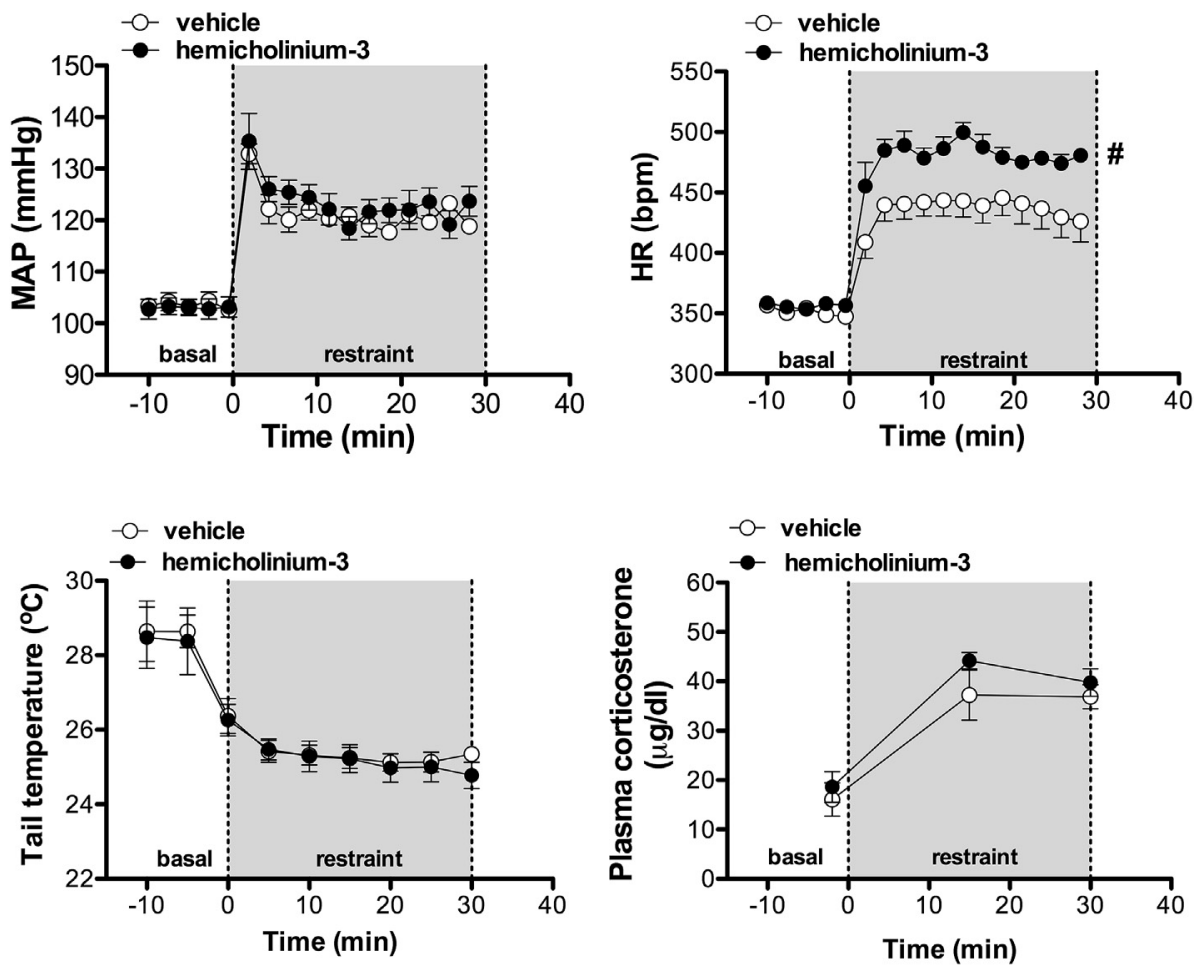

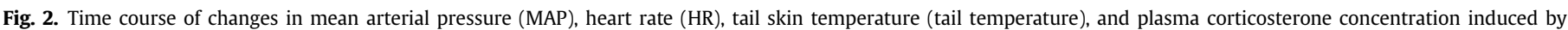

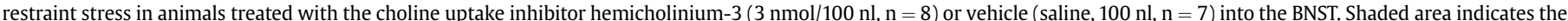

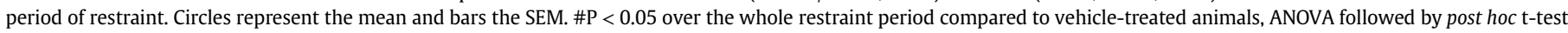

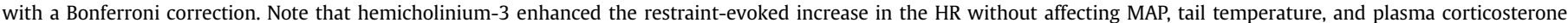
responses.
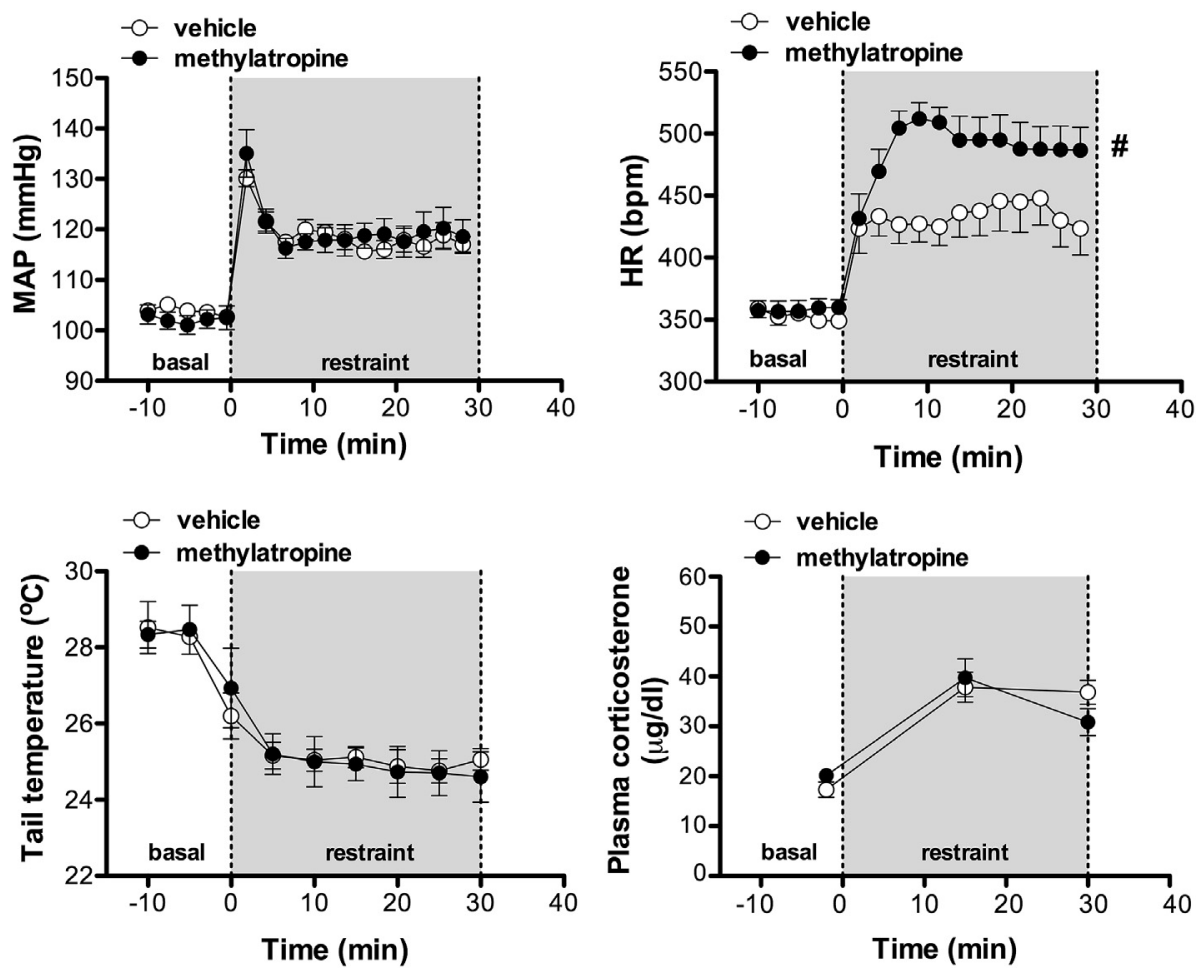

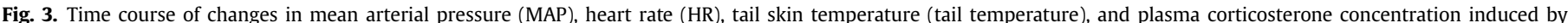

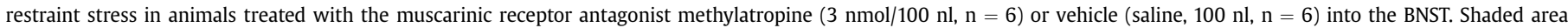

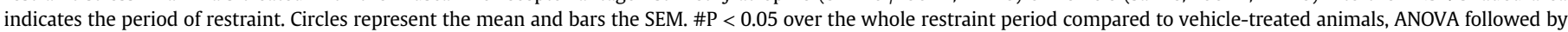

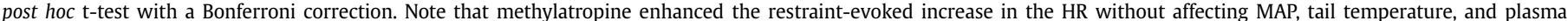
corticosterone responses. 

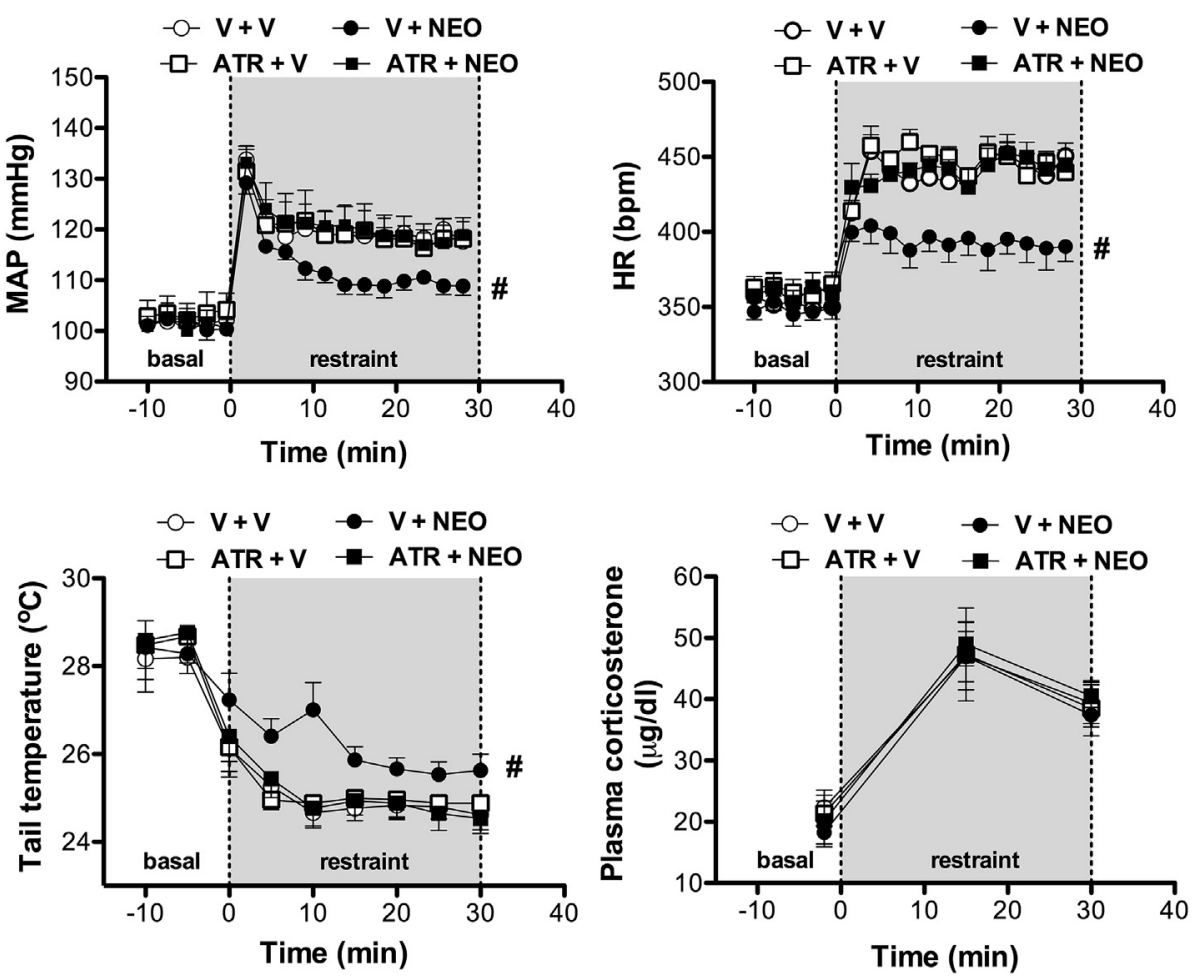

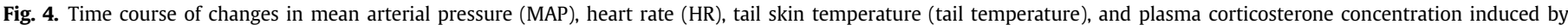

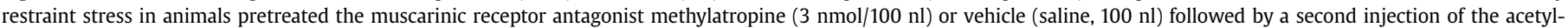

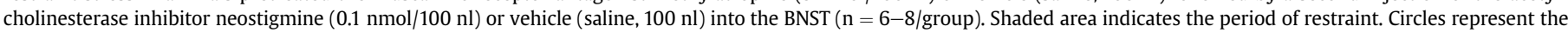

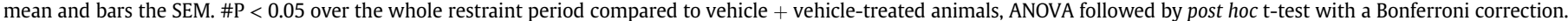

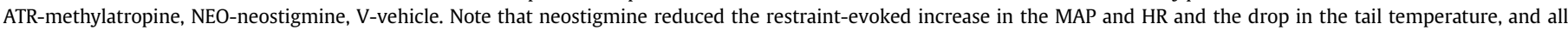
these effects were inhibited by local pretreatment with methylatropine.

evoked increase in the $\mathrm{HR}\left(\mathrm{F}_{(1,221)}=89.98, \mathrm{P}<0.0001\right)$, without affecting MAP $\left(\mathrm{F}_{(1,221)}=2.87, \mathrm{P}>0.05\right)$, skin temperature $\left(\mathrm{F}_{(1,117)}=0.48, \mathrm{P}>0.05\right)$, and plasma corticosterone responses $\left(F_{(1,39)}=2.57, \mathrm{P}>0.05\right)$ (Fig. 2). Analysis did not identify interaction between treatment and time for $\operatorname{MAP}\left(\mathrm{F}_{(16,221)}=0.66, \mathrm{P}>0.05\right), \mathrm{HR}$ $\left(F_{(16,221)}=1.78, P>0.05\right)$, cutaneous temperature $\left(F_{(8,117)}=0.07\right.$, $\mathrm{P}>0.05)$, and plasma corticosterone $\left(\mathrm{F}_{(2,39)}=0.30, \mathrm{P}>0.05\right)$ measurements.

\subsubsection{Methylatropine}

Bilateral microinjection of the muscarinic cholinergic receptor antagonist methylatropine $(3 \mathrm{nmol} / 100 \mathrm{nl})$ into the BNST did not alter baseline values of either MAP, HR, tail skin temperature, or plasma corticosterone (Table 1). Restraint increased the MAP $\left(\mathrm{F}_{(16,170)}=26.62, \mathrm{P}<0.0001\right), \mathrm{HR}\left(\mathrm{F}_{(16,170)}=19.32, \mathrm{P}<0.0001\right)$, and plasma corticosterone $\left(\mathrm{F}_{(2,30)}=32.02, \mathrm{P}<0.0001\right)$; and decreased the tail skin temperature $\left(F_{(8,90)}=15.93, P<0.0001\right)$ (Fig. 3$)$. BNST treatment with methylatropine enhanced the restraint-evoked increase in the $\operatorname{HR}\left(\mathrm{F}_{(1,170)}=54.20, \mathrm{P}<0.0001\right)$, without affecting MAP $\left(F_{(1,170)}=0.04, P>0.05\right)$, cutaneous temperature $\left(F_{(1,90)}=0.001\right.$, $\mathrm{P}>0.05)$, and plasma corticosterone responses $\left(F_{(1,30)}=0.03\right.$, $P>0.05)$ (Fig. 3). Analysis did not identify interaction between treatment and time for $\mathrm{MAP}\left(\mathrm{F}_{(16,170)}=0.49, \mathrm{P}>0.05\right)$, HR $\left(F_{(16,170)}=1.69, P>0.05\right)$, skin temperature $\left(F_{(8,90)}=0.18, P>0.05\right)$, and plasma corticosterone $\left(\mathrm{F}_{(2,30)}=1.73, \mathrm{P}>0.05\right)$ measurements.

\subsection{Effect of unilateral microinjection into the BNST of methylatropine and/or neostigmine in cardiovascular and neuroendocrine responses to acute restraint stress}

Unilateral microinjection of the acetylcholinesterase inhibitor neostigmine $(0.1 \mathrm{nmol} / 100 \mathrm{nl})$ into the BNST following local pretreatment with either vehicle or methylatropine did not alter baseline values of either MAP, HR, tail skin temperature, or plasma corticosterone (Table 1). Restraint increased the MAP $\left(\mathrm{F}_{(16,374)}=33.13, \mathrm{P}<0.0001\right), \mathrm{HR}\left(\mathrm{F}_{(16,374)}=58.93, \mathrm{P}<0.0001\right)$, and plasma corticosterone $\left(\mathrm{F}_{(2,66)}=51.11, \mathrm{P}<0.0001\right)$; and decreased the tail skin temperature $\left(\mathrm{F}_{(8,198)}=39.20, \mathrm{P}<0.0001\right)$ (Fig. 4). Analysis indicated an effect of BNST pharmacological treatments in $\operatorname{MAP}\left(\mathrm{F}_{(3,374)}=22.10, \mathrm{P}<0.0001\right), \mathrm{HR}\left(\mathrm{F}_{(3,374)}=78.77, \mathrm{P}<0.0001\right)$, and tail temperature $\left(\mathrm{F}_{(3,198)}=8.9, \mathrm{P}<0.0001\right)$ responses (Fig. 4$)$. However, treatments did not affect the increase in plasma corticosterone concentration $\left(\mathrm{F}_{(3,66)}=0.24, \mathrm{P}>0.05\right)$ (Fig. 4). Post hoc analysis revealed that BNST treatment with neostigmine reduced the increase in the MAP $(\mathrm{P}<0.05)$ and $\mathrm{HR}(\mathrm{P}<0.05)$ and the drop in the tail skin temperature $(P<0.05)$ evoked by restraint stress. Unilateral microinjection of methylatropine into the BNST did not affect any parameter analyzed $(P>0.05$ ) (Fig. 4). However, methylatropine pretreatment inhibited neostigmine effects in MAP $(P>0.05), H R(P>0.05)$, and tail temperature $(P>0.05)$ responses (Fig. 4).

\subsection{Effect of bilateral microinjection of hemicholinium-3 or methylatropine into the BNST on behavioral responses to acute restraint stress}

The acute restraint stress evoked a significant decrease in the percentage of time spent $\left(\mathrm{F}_{(3,41)}=6.10, \mathrm{P}<0.001\right)$ and number of entries $\left(F_{(3,41)}=3.21, P<0.03\right)$ in the open arms of the EPM in the vehicle-treated animals, when compared with naïve animals (Fig. 5). Acute restraint stress did not affect the number of entries in the enclosed arms $\left(\mathrm{F}_{(3,41)}=1.44, \mathrm{P}>0.05\right)$ (Fig. 5). BNST treatment 

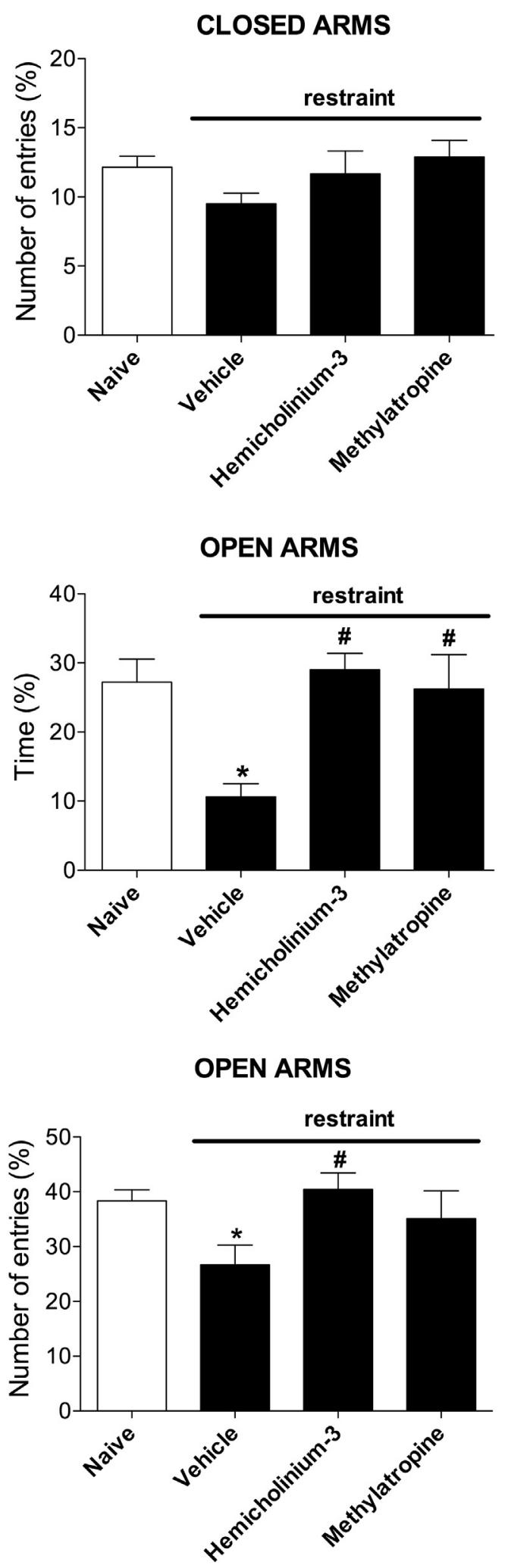

Fig. 5. Effect of bilateral microinjection of the choline uptake inhibitor hemicholinium$3(3 \mathrm{nmol} / 100 \mathrm{nl}, \mathrm{n}=9$ ), the muscarinic receptor antagonist methylatropine ( $3 \mathrm{nmol} /$ $100 \mathrm{nl}, \mathrm{n}=9$ ), or vehicle (saline, $100 \mathrm{nl}, \mathrm{n}=10$ ) into the BNST on behavioral changes in the elevated plus-maze (EPM) evoked by acute restraint stress. Animals that were not exposed to restraint stress (naïve group, $\mathrm{n}=14$ ) were used as control. Pharmacological treatment of the BNST was realized $10 \mathrm{~min}$ before the restraint onset. Columns represent the mean and bars the SEM. ${ }^{*} \mathrm{P}<0.05$ vs naïve group, $\# \mathrm{P}<0.05$ vs vehicle group. One-way ANOVA followed by post hoc t-test with a Bonferroni correction. Note that restraint stress reduced the exploration of the open arms (anxiogenic-like effect), and BNST treatment with either hemicholinium-3 or methylatropine reverted this effect. with either hemicholinium-3 or methylatropine reverted restraintevoked decrease in the percentage of time spent (hemicholinium3: $\mathrm{P}<0.05$, methylatropine: $\mathrm{P}<0.05$ ) and number of entries in the open arms (hemicholinium-3: $\mathrm{P}<0.05$, methylatropine: $\mathrm{P}<0.05$ ) of the EPM (Fig. 5).

\section{Discussion}

The present study provides the first evidence that cholinergic signaling within the BNST modulates physiological and behavioral responses evoked by emotional stress. We have demonstrated that bilateral microinjection into the BNST of either the choline uptake inhibitor hemicholinium-3 or the muscarinic receptor antagonist methylatropine enhanced the tachycardiac response and inhibited the anxiogenic-like effect in the EPM evoked by acute restraint stress. Neither hemicholinium-3 nor methylatropine affected the responses of increase in MAP and plasma corticosterone concentration and the drop in tail skin temperature. Conversely, facilitation of local cholinergic signaling by microinjection of the acetylcholinesterase inhibitor neostigmine into the BNST reduced restraint-evoked pressor and tachycardiac responses and the fall in tail cutaneous temperature, without affecting the increase in plasma corticosterone. All effects of neostigmine were inhibited by local BNST pretreatment with methylatropine.

The activation of the HPA axis is a primary response during stress (Dickerson and Kemeny, 2004; Ulrich-Lai and Herman, 2009). The BNST has been implicated in HPA axis response to stress (Choi et al., 2007; Crestani et al., 2013; Ulrich-Lai and Herman, 2009). The BNST sends direct projections to corticotropin-releasing hormone $(\mathrm{CRH})$ containing parvocellular regions of the hypothalamic paraventricular nucleus (PVN) (Dong et al., 2001b; Dong and Swanson, 2006), thus providing evidence of a mechanism for direct actions on HPA axis output. The control of HPA response by BNST is region specific (Crestani et al., 2013; Ulrich-Lai and Herman, 2009). For instance, chemical lesion of anterior division of the BNST reduced restraint-induced increase in circulating adrenocorticotrophic hormone (ACTH) and corticosterone and PVN c-fos mRNA induction, whereas acute inhibition by local muscimol microinjection or lesion of the posterior BNST division resulted in elevated corticosterone and ACTH release and increased parvocellular PVN Fos activation following acute restraint stress (Choi et al., 2007; Crestani et al., 2013). Most of our microinjection sites reached the anterior division of the BNST, which is the critical BNST region involved in autonomic control (Crestani et al., 2013; Dong et al., 2001a), and plays a facilitatory role in HPA activation during restraint stress (Choi et al., 2007; Crestani et al., 2013). However, neither inhibition nor facilitation of cholinergic signaling within the BNST affected corticosterone response to restraint, thus indicating that BNST control of HPA response to stress is mediated by mechanisms other than local cholinergic signaling. Previous studies described a modulation of HPA response to stress by local noradrenergic, GABAergic, and peptidergic mechanisms within the BNST (Cecchi et al., 2002; Crestani et al., 2013; Khoshbouei et al., 2002).

Present findings indicate that BNST cholinergic neurotransmission, acting via local muscarinic receptors, plays an inhibitory role in HR response to restraint stress. Similarly, we have previously reported that acute BNST neurotransmission inhibition caused by local treatment with $\mathrm{CoCl}_{2}$ enhanced restraint-evoked tachycardia, without affecting the pressor response (Crestani et al., 2009). Thus, local cholinergic signaling seems to be an important local neurochemical mechanism mediating the BNST inhibitory influence in cardiac responses to stress. However, BNST treatment with a selective $\alpha_{1}$-adrenoceptor antagonist also facilitated restraint-evoked tachycardiac response (Crestani et al., 2009), thus indicating that local noradrenergic mechanisms also contribute to control of 
stress-induced cardiac responses by the BNST. To the best of our knowledge, a possible interaction between cholinergic and noradrenergic signaling within the BNST has never been described. Nevertheless, recent results have shown that endogenously released acetylcholine within the BNST suppresses local glutamate neurotransmission through activation of presynaptic muscarinic receptors (Guo et al., 2012). In the same way, noradrenaline acting through $\alpha$-adrenoceptors has predominantly an inhibitory influence in the firing activity of BNST neurons (Casada and Dafny, 1993; Sawada and Yamamoto, 1981), which is mediated by both facilitation of local $\mathrm{GABA}_{\mathrm{A}}$ receptor-related inhibitory actions (Dumont and Williams, 2004) and reduction of glutamate neurotransmission (Egli et al., 2005; Forray et al., 1999; Krawczyk et al., 2011; Shields et al., 2009). These results support the findings of a similar influence of BNST muscarinic receptors and $\alpha_{1}$-adrenoceptors in restraint-evoked tachycardiac response.

Decreased exploration of open arms in the EPM has been reported following exposure of rodents to different stressors, including the restraint stress (Korte and De Boer, 2003). This effect is inhibited by anxiolytic substances and potentiated by anxiogenic drugs, thus suggesting an anxiogenic-like effect (Korte and De Boer, 2003). The BNST has been proposed as a critical structure for the etiology of several anxiety disorders, including anxiety generated by stress (Adhikari, 2014; Davis et al., 2010; Hammack et al., 2010; Kash et al., 2015). Indeed, previous data have reported an involvement of the BNST in anxiogenic effect in the EPM induced by acute inescapable shock and immobilization stress (Cecchi et al., 2002; Hammack et al., 2004; Khoshbouei et al., 2002). Nevertheless, present study provides the first evidence for a role of local cholinergic signaling in BNST control of stress-evoked anxiogeniclike effect.

The inhibition of behavioral reactivity to stress in animals treated with inhibitors of cholinergic signaling indicates a proaversive effect of acetylcholine released within the BNST during stress. This finding contrasts with cardiovascular results, which indicated an inhibitory influence of BNST cholinergic neurotransmission in restraint-evoked tachycardia. Therefore, our results suggest that distinct neural pathways mediate the control by BNST of cardiovascular and behavioral responses to stress. This assumption is supported by recent findings indicating divergent BNST outputs controlling physiological functions and behavioral responses (Kim et al., 2013). For instance, results obtained through optogenetic stimulation suggested that projections from BNST to lateral hypothalamus modulate behavioral responses in the EPM without affecting respiratory rate (physiological measurement) (Kim et al., 2013). On the other hand, stimulation of BNST projections to parabrachial nucleus reduced the respiratory rate increase in an anxiogenic environment without affecting behavior in the EPM (Kim et al., 2013). Our findings are further supported by studies reporting a segregation of autonomic and behavioral responses to aversive threats in other limbic structures, such as the lateral septal area and dorsal and ventral hippocampus (Reis et al., 2011; Resstel et al., 2008; Scopinho et al., 2013). Furthermore, the absence of a modulation of corticosterone response by BNST cholinergic neurotransmission indicates a further dissociation in control of neuroendocrine adjustments in relation to cardiovascular and behavioral responses.

The BNST is reciprocally connected with the central amygdala and medial amygdala and receives innervation from the hippocampus and medial prefrontal cortex (MPFC) (Dong et al., 2001a; Myers et al., 2014). Moreover, BNST neurons project to many hypothalamic and brainstem nuclei involved in control of autonomic and neuroendocrine functions and behavioral responses (Dong et al., 2001b; Dong and Swanson, 2006). Limbic structures (such as amygdala, hippocampus, and MPFC) have little direct anatomical connections with primary stress effector regions in hypothalamus and brainstem (Myers et al., 2012; Ulrich-Lai and Herman, 2009). Therefore, the BNST has been proposed as a relay station between limbic processing of emotional information and elaboration of physiological and behavioral responses to stress (Adhikari, 2014; Choi et al., 2007; Crestani et al., 2013; Myers et al., 2012; UlrichLai and Herman, 2009). Indeed, BNST ablation inhibits cardiovascular and neuroendocrine responses elicited by amygdala, hippocampus, and MPFC (Radley et al., 2009; Roder and Ciriello, 1993; Zhu et al., 2001). Moreover, MPFC lesion reduces restraint-evoked activation of BNST neurons (Figueiredo et al., 2003), and inhibition of either the medial amygdala or MPFC evokes effects in cardiovascular responses to restraint stress similar to those presently reported (i.e., facilitation of stress-evoked tachycardia) (Fortaleza et al., 2009; Tavares and Correa, 2006). Also, previous results have indicated an involvement of the hippocampus and MPFC in anxiogenic effect of the restraint stress in the EPM (Fogaca et al., 2014; Padovan et al., 2000). Thus, although evidence that limbic inputs to the BNST are predominantly glutamatergic and GABAergic (Myers et al., 2014), our results indicate that local cholinergic signaling is important in local processing of limbic information in the BNST for elaboration of cardiovascular and behavioral responses.

Results obtained with the choline uptake inhibitor and the muscarinic receptor antagonist provided evidence that physiological release of acetylcholine within the BNST during restraint selectively modulates tachycardiac response and anxiogenic-like effect, without affecting blood pressure and sympatheticmediated cutaneous vasoconstriction responses. Nevertheless, facilitation of BNST cholinergic neurotransmission by local treatment with the acetylcholinesterase inhibitor neostigmine affected both blood pressure, HR, and cutaneous temperature responses. Therefore, although the evidence obtained via the blockade of cholinergic neurotransmission indicating a specific role of this neurochemical mechanism in the BNST in controlling cardiac response to restraint, results of neostigmine indicate that BNST cholinergic neurotransmission is also able to modulate arterial pressure and cutaneous vasoconstriction responses during emotional stress. Furthermore, all effects of neostigmine were inhibited by pretreatment with methylatropine, thus reinforcing evidence of a primary role of muscarinic receptors in mediating acetylcholine control of stress responses within the BNST. The absence of effect of neostigmine in corticosterone response further support the idea that BNST control of HPA axis response is mediated by mechanisms other than cholinergic neurotransmission.

In summary, the present results indicate that cholinergic signaling within the BNST, acting via local muscarinic receptors, differently modulate cardiovascular responses and emotional consequences of stress. Our data suggest an inhibitory role of BNST cholinergic neurotransmission in tachycardiac response to restraint stress, whereas this signaling mechanism is involved in etiology of stress-evoked anxiogenic-like effect. Present findings also provide evidence that BNST control of HPA axis activation during stress is mediated by mechanisms other than local cholinergic neurotransmission.

\section{Acknowledgments}

The authors wish to thank Elisabete Lepera and Rosana Silva for technical assistance. This work was supported by grants \# 2012/ 50549-6 FAPESP/MCTI/CNPq, 2012/14376-0, 2013/01283-6, and 2015/05922-9 FAPESP; 456405/2014-3 and 478696/2013-2 CNPq, and PADC-FCF UNESP. RLNS is a CNPq research fellow (305597/ 2012-4). 


\section{References}

Adhikari, A., 2014. Distributed circuits underlying anxiety. Front. Behav. Neurosci. 8, 112.

Alves, F.H., Crestani, C.C., Busnardo, C., Antunes-Rodrigues, J., Gomes, F.V., Resstel, L.B., Correa, F.M., 2011. Hypothalamic supraoptic but not paraventricular nucleus is involved in cardiovascular responses to carbachol microinjected into the bed nucleus of stria terminalis of unanesthetized rats. Brain Res. 1393 $31-43$.

Alves, F.H., Crestani, C.C., Resstel, L.B., Correa, F.M., 2007. Cardiovascular effects of carbachol microinjected into the bed nucleus of the stria terminalis of the rat brain. Brain Res. 1143, 161-168.

Bhatnagar, S., Costall, B., Smythe, J.W., 1997. Hippocampal cholinergic blockade enhances hypothalamic-pituitary-adrenal responses to stress. Brain Res. 766, 244-248.

Blessing, W.W., 2003. Lower brainstem pathways regulating sympathetically mediated changes in cutaneous blood flow. Cell. Mol. Neurobiol. 23, 527-538.

Busnardo, C., Alves, F.H., Crestani, C.C., Scopinho, A.A., Resstel, L.B., Correa, F.M., 2013. Paraventricular nucleus of the hypothalamus glutamate neurotransmission modulates autonomic, neuroendocrine and behavioral responses to acute restraint stress in rats. Eur. Neuropsychopharmacol. 23, 1611-1622.

Casada, J.H., Dafny, N., 1993. Muscarinic receptors mediate the effect of acetylcholine (ACh) on neurons of the bed nucleus of the stria terminalis (BNST). Brain Res. 631, 124-128.

Cecchi, M., Khoshbouei, H., Javors, M., Morilak, D.A., 2002. Modulatory effects of norepinephrine in the lateral bed nucleus of the stria terminalis on behavioral and neuroendocrine responses to acute stress. Neuroscience 112, 13-21.

Choi, D.C., Furay, A.R., Evanson, N.K., Ostrander, M.M., Ulrich-Lai, Y.M., Herman, J.P., 2007. Bed nucleus of the stria terminalis subregions differentially regulate hypothalamic-pituitary-adrenal axis activity: implications for the integration of limbic inputs. J. Neurosci. 27, 2025-2034.

Clarke, P.B. Schwartz, R.D., Paul, S.M., Pert, C.B. Pert, A., 1985, Nicotinic binding in rat brain: autoradiographic comparison of $[3 \mathrm{H}]$ acetylcholine, $[3 \mathrm{H}]$ nicotine, and [125I]-alpha-bungarotoxin. J. Neurosci. 5, 1307-1315.

Crestani, C.C., Alves, F.H., Gomes, F.V., Resstel, L.B., Correa, F.M., Herman, J.P., 2013. Mechanisms in the bed nucleus of the stria terminalis involved in control of autonomic and neuroendocrine functions: a review. Curr. Neuropharmacol. 11, $141-159$.

Crestani, C.C. Alves, F.H. Tavares, R.F., Correa, F.M., 2009. Role of the bed nucleus of the stria terminalis in the cardiovascular responses to acute restraint stress in rats. Stress 12, 268-278.

Crestani, C.C., Tavares, R.F., Alves, F.H., Resstel, L.B., Correa, F.M., 2010. Effect of acute restraint stress on the tachycardiac and bradycardiac responses of the baroreflex in rats. Stress 13, 61-72.

Dampney, R.A., Horiuchi, J., McDowall, L.M., 2008. Hypothalamic mechanisms coordinating cardiorespiratory function during exercise and defensive behaviour. Auton. Neurosci. 142, 3-10.

Danese, A., McEwen, B.S., 2012. Adverse childhood experiences, allostasis, allostatic load, and age-related disease. Physiol. Behav. 106, 29-39.

Davis, M., Walker, D.L., Miles, L., Grillon, C., 2010. Phasic vs sustained fear in rats and humans: role of the extended amygdala in fear vs anxiety. Neuropsychopharmacology 35, 105-135.

Dickerson, S.S., Kemeny, M.E., 2004. Acute stressors and cortisol responses: theoretical integration and synthesis of laboratory research. Psychol. Bull. 130, $355-391$.

Dong, H.W., Petrovich, G.D., Swanson, L.W., 2001a. Topography of projections from amygdala to bed nuclei of the stria terminalis. Brain Res. Brain Res. Rev. 38 $192-246$.

Dong, H.W., Petrovich, G.D., Watts, A.G., Swanson, L.W., 2001b. Basic organization of projections from the oval and fusiform nuclei of the bed nuclei of the stria terminalis in adult rat brain. J. Comp. Neurol. 436, 430-455.

Dong, H.W., Swanson, L.W., 2006. Projections from bed nuclei of the stria terminalis, anteromedial area: cerebral hemisphere integration of neuroendocrine, autonomic, and behavioral aspects of energy balance. J. Comp. Neurol. 494, 142-178.

Dos Reis, D.G., Fortaleza, E.A., Tavares, R.F., Correa, F.M., 2014. Role of the autonomic nervous system and baroreflex in stress-evoked cardiovascular responses in rats. Stress 17, 362-372.

Dumont, E.C., Williams, J.T., 2004. Noradrenaline triggers GABAA inhibition of bed nucleus of the stria terminalis neurons projecting to the ventral tegmental area. J. Neurosci. 24, 8198-8204.

Egli, R.E., Kash, T.L., Choo, K., Savchenko, V., Matthews, R.T., Blakely, R.D. Winder, D.G., 2005. Norepinephrine modulates glutamatergic transmission in the bed nucleus of the stria terminalis. Neuropsychopharmacology 30 , $657-668$.

Fernandes, K.B., Tavares, R.F., Correa, F.M., 2005. The lateral septal area is involved in the pressor pathway activated by microinjection of norepinephrine into the rat brain cingulate cortex. Neuropharmacology 49, 564-571.

Figueiredo, H.F., Bruestle, A., Bodie, B., Dolgas, C.M., Herman, J.P., 2003. The medial prefrontal cortex differentially regulates stress-induced c-fos expression in the forebrain depending on type of stressor. Eur. J. Neurosci. 18, 2357-2364.

Fogaca, M.V., Reis, F.M., Campos, A.C., Guimaraes, F.S., 2014. Effects of intraprelimbic prefrontal cortex injection of cannabidiol on anxiety-like behavior: involvement of 5HT1A receptors and previous stressful experience. Eur. Neuropsychopharmacol. 24, 410-419.
Forray, M.I., Bustos, G., Gysling, K., 1999. Noradrenaline inhibits glutamate release in the rat bed nucleus of the stria terminalis: in vivo microdialysis studies. J. Neurosci. Res. 55, 311-320.

Fortaleza, E.A., Tavares, R.F., Correa, F.M., 2009. The medial amygdaloid nucleus modulates cardiovascular responses to acute restraint in rats. Neuroscience 159, $717-726$.

Guo, J.D., Hazra, R., Dabrowska, J., Muly, E.C., Wess, J., Rainnie, D.G., 2012. Presynaptic muscarinic $\mathrm{M}(2)$ receptors modulate glutamatergic transmission in the bed nucleus of the stria terminalis. Neuropharmacology 62, 1671-1683.

Hammack, S.E., Richey, K.J., Watkins, L.R., Maier, S.F., 2004. Chemical lesion of the bed nucleus of the stria terminalis blocks the behavioral consequences of uncontrollable stress. Behav. Neurosci. 118, 443-448.

Hammack, S.E., Roman, C.W., Lezak, K.R., Kocho-Shellenberg, M., Grimmig, B., Falls, W.A., Braas, K., May, V., 2010. Roles for pituitary adenylate cyclaseactivating peptide (PACAP) expression and signaling in the bed nucleus of the stria terminalis (BNST) in mediating the behavioral consequences of chronic stress. J. Mol. Neurosci. 42, 327-340.

Helm, K.A., Ziegler, D.R., Gallagher, M., 2004. Habituation to stress and dexamethasone suppression in rats with selective basal forebrain cholinergic lesions. Hippocampus 14, 628-635.

Joels, M., Baram, T.Z., 2009. The neuro-symphony of stress. Nat. Rev. Neurosci. 10, 459-466.

Kash, T.L., Pleil, K.E., Marcinkiewcz, C.A., Lowery-Gionta, E.G., Crowley, N., Mazzone, C., Sugam, J., Hardaway, J.A., McElligott, Z.A., 2015. Neuropeptide regulation of signaling and behavior in the BNST. Mol. Cells 38, 1-13.

Khoshbouei, H., Cecchi, M., Morilak, D.A., 2002. Modulatory effects of galanin in the lateral bed nucleus of the stria terminalis on behavioral and neuroendocrine responses to acute stress. Neuropsychopharmacology 27, 25-34.

Kim, S.Y., Adhikari, A., Lee, S.Y., Marshel, J.H., Kim, C.K., Mallory, C.S., Lo, M., Pak, S., Mattis, J., Lim, B.K., Malenka, R.C., Warden, M.R., Neve, R., Tye, K.M., Deisseroth, K., 2013. Diverging neural pathways assemble a behavioural state from separable features in anxiety. Nature 496, 219-223.

Korte, S.M., De Boer, S.F., 2003. A robust animal model of state anxiety: fearpotentiated behaviour in the elevated plus-maze. Eur. J. Pharmacol. 463, $163-175$.

Krawczyk, M., Georges, F., Sharma, R., Mason, X., Berthet, A., Bezard, E., Dumont, E.C., 2011. Double-dissociation of the catecholaminergic modulation of synaptic transmission in the oval bed nucleus of the stria terminalis. J. Neurophysiol. 105, 145-153.

Kubo, T., Okatani, H., Kanaya, T., Hagiwara, Y., Fukumori, R., Goshima, Y., 2003. Cholinergic mechanism in the lateral septal area is involved in the stressinduced blood pressure increase in rats. Brain Res. Bull. 59, 359-364.

Mark, G.P., Rada, P.V., Shors, T.J., 1996. Inescapable stress enhances extracellular acetylcholine in the rat hippocampus and prefrontal cortex but not the nucleus accumbens or amygdala. Neuroscience $74,767-774$.

Myers, B., Mark Dolgas, C., Kasckow, J., Cullinan, W.E., Herman, J.P., 2014. Central stress-integrative circuits: forebrain glutamatergic and GABAergic projections to the dorsomedial hypothalamus, medial preoptic area, and bed nucleus of the stria terminalis. Brain Struct. Funct. 219, 1287-1303.

Myers, B., McKlveen, J.M., Herman, J.P., 2012. Neural regulation of the stress response: the Many Faces of Feedback. Cell. Mol. Neurobiol. 32 (5), 683-694.

Nail-Boucherie, K., Dourmap, N., Jaffard, R., Costentin, J., 2000. Contextual fear conditioning is associated with an increase of acetylcholine release in the hippocampus of rat. Brain Res. Cogn. Brain Res. 9, 193-197.

Nasimi, A., Hatam, M., 2011. The role of the cholinergic system of the bed nucleus of the stria terminalis on the cardiovascular responses and the baroreflex modulation in rats. Brain Res. 1386, 81-88.

Ohata, H., Shibasaki, T., 2011. Involvement of CRF2 receptor in the brain regions in restraint-induced anorexia. Neuroreport 22, 494-498.

Oliveira, L.A., Almeida, J., Benini, R., Crestani, C.C., 2015. CRF and CRF receptors in the bed nucleus of the stria terminalis modulate the cardiovascular responses to acute restraint stress in rats. Pharmacol. Res. 95-96, 53-62.

Padovan, C.M., Del Bel, E.A., Guimaraes, F.S., 2000. Behavioral effects in the elevated plus maze of an NMDA antagonist injected into the dorsal hippocampus: influence of restraint stress. Pharmacol. Biochem. Behav. 67, 325-330.

Padovan, C.M., Guimaraes, F.S., 2000. Restraint-induced hypoactivity in an elevated plus-maze. Braz. J. Med. Biol. Res. 33, 79-83.

Paxinos, G., Watson, C., 1997. The Rat Brain in Stereotaxic Coordinates. Academic Press, Sidney, Australia.

Pellow, S., File, S.E., 1986. Anxiolytic and anxiogenic drug effects on exploratory activity in an elevated plus-maze: a novel test of anxiety in the rat. Pharmacol. Biochem. Behav, 24, 525-529.

Radley, J.J., Gosselink, K.L., Sawchenko, P.E., 2009. A discrete GABAergic relay mediates medial prefrontal cortical inhibition of the neuroendocrine stress response. J. Neurosci. 29, 7330-7340.

Reis, D.G., Scopinho, A.A., Guimaraes, F.S., Correa, F.M., Resstel, L.B., 2011. Behavioral and autonomic responses to acute restraint stress are segregated within the lateral septal area of rats. PLoS One 6, e23171.

Resstel, L.B., Joca, S.R., Correa, F.M., Guimaraes, F.S., 2008. Effects of reversible inactivation of the dorsal hippocampus on the behavioral and cardiovascular responses to an aversive conditioned context. Behav. Pharmacol. 19, 137-144.

Roder, S., Ciriello, J., 1993. Contribution of bed nucleus of the stria terminalis to the cardiovascular responses elicited by stimulation of the amygdala. J. Auton. Nerv. Syst. $45,61-75$.

Ruggiero, D.A., Giuliano, R., Anwar, M., Stornetta, R., Reis, D.J., 1990. Anatomical 
substrates of cholinergic-autonomic regulation in the rat. J. Comp. Neurol. 292, $1-53$.

Sarnyai, Z., Biro, E., Penke, B., Telegdy, G., 1992. The cocaine-induced elevation of plasma corticosterone is mediated by endogenous corticotropin-releasing factor (CRF) in rats. Brain Res. 589, 154-156.

Sawada, S., Yamamoto, C., 1981. Postsynaptic inhibitory actions of catecholamines and opioid peptides in the bed nucleus of the stria terminalis. Exp. Brain Res. 41, 264-270.

Schadt, J.C., Hasser, E.M., 1998. Hemodynamic effects of acute stressors in the conscious rabbit. Am. J. Physiol. 274, R814-R821.

Scopinho, A.A., Lisboa, S.F., Guimaraes, F.S., Correa, F.M., Resstel, L.B., Joca, S.R., 2013. Dorsal and ventral hippocampus modulate autonomic responses but not behavioral consequences associated to acute restraint stress in rats. PLoS One 8, e77750.

Sevgi, S., Ozek, M., Eroglu, L., 2006. L-NAME prevents anxiety-like and depressionlike behavior in rats exposed to restraint stress. Methods Find. Exp. Clin. Pharmacol. 28, 95-99.

Shields, A.D., Wang, Q., Winder, D.G., 2009. alpha2A-adrenergic receptors heterosynaptically regulate glutamatergic transmission in the bed nucleus of the stria terminalis. Neuroscience 163, 339-351.

Spencer Jr. D.G., Horvath, E., Traber, J., 1986. Direct autoradiographic determination of M1 and M2 muscarinic acetylcholine receptor distribution in the rat brain: relation to cholinergic nuclei and projections. Brain Res. 380, 59-68.

Sterling, P., 2012. Allostasis: a model of predictive regulation. Physiol. Behav. 106 $5-15$.

Tavares, R.F., Correa, F.M., 2006. Role of the medial prefrontal cortex in cardiovascular responses to acute restraint in rats. Neuroscience 143, 231-240.

Ulrich-Lai, Y.M., Herman, J.P., 2009. Neural regulation of endocrine and autonomic stress responses. Nat. Rev. Neurosci. 10, 397-409.

Vianna, D.M., Carrive, P., 2005. Changes in cutaneous and body temperature during and after conditioned fear to context in the rat. Eur. J. Neurosci. 21, 2505-2512.

Wamsley, J.K., Zarbin, M.A., Kuhar, M.J., 1984. Distribution of muscarinic cholinergic high and low affinity agonist binding sites: a light microscopic autoradiographic study. Brain Res. Bull. 12, 233-243.

Zhu, W., Umegaki, H., Suzuki, Y., Miura, H., Iguchi, A., 2001. Involvement of the bed nucleus of the stria terminalis in hippocampal cholinergic system-mediated activation of the hypothalamo-pituitary-adrenocortical axis in rats. Brain Res. 916, 101-106. 